\title{
Twin research in Norway with special emphasis on psychiatric studies
}

\author{
Einar Kringlen \\ University of Oslo, Boks 1072 Blindern, 0316 Oslo \\ einar.kringlen@medisin.uio.no
}

This is an open access article distributed under the Creative Commons Attribution Licence, which permits unrestricted use, distribution, and reproduction in any medium, provided the original work is properly cited.

The scientific study of twins is a comparatively recent phenomenon and is generally regarded as dating from the work of Sir Francis Galton (1822-1911), whose 1875 paper The history of twins as a criterion of the relative powers of nature and nurture - and classic work Inquiries into human faculty and its development from 1883 formed the starting point for modern twin research. Galton was the first to realize that monozygotic twins probably resulted from the splitting of a single fertilized ovum, while dizygotic twins resulted from the fertilization of two separate ova.

Twin studies together with adoption studies are the best methods in exploring the relationship between heredity and environment in health and disease, but paradoxically these methods have been carried out particularly in the study of personality and mental illness. The reason might be that psychologists and psychiatrists have been more interested in the question of etiology than somatic physicians. Rarely does one witness hard fight between geneticists and environmentalists in somatic medicine whereas the opposite is true in psychiatry and psychology. The reason might be that research findings in these fields might affect our philosophy of life.

Francis Galton, a cousin of Darwin, held the view that heredity is more important than environment "nature prevails enormously over nurture". He makes, however, this important qualification: "when the difference of nurture does not exceed what is commonly found among persons of the same rank of society and in the same country." His ideas were partly based upon twin studies and personal impressions.

\section{PsyChIATRIC STUdies}

The so-called classical twin method was developed in the 1920s, and systematic studies were embarked upon by American, British and German investigators. Monozygotic (MZ) and dizygotic (DZ) twin pairs were compared statistically in respect of their concordance for the traits or illness in question. Concordance is usually expressed as the rate of similar occurrence in both twins, or in the case of measurable traits as the average intrapair difference. Significantly higher concordance rates in the group of MZ twins than in DZ twins have been regarded as evidence in support of a hereditary background of the traits concerned.

In psychiatry twin studies focused attention on the prevailing severe mental disorders, such as schizophre- nia and manic depressive psychosis (bipolar illness). Considerable higher concordance rates for MZs than DZs were reported by Luxenburger (1928), Rosanoff et al (1934-35) and Slater (1953). The most wellknown studies after the Second World War were carried out by Kallmann $(1946,1950)$ who reported a concordance rate of 86 percent in MZs and 14 percent in DZs with regard to schizophrenia. Kallmann's large-scale twin studies had a far-reaching influence on psychiatry until the 1960s when Rosenthal (1961, 1962) in a series of critical papers drew special attention to the importance of sampling in twin studies, and argued convincingly that the classical studies by and large showed misleadingly high concordance figures with respect to schizophrenia. Kallmann's data were based upon reports from the staffs of mental hospitals in the state of New York, not on a birth register. Thus he was bound to obtain a preponderance of concordant cases. Discordant pairs are often missed simply because one does not know that the case is a twin. As pointed out by Kringlen (1964) there are additional sources of errors in the Kallmann studies, errors that tend to inflate the concordance figures. After the Second World War the schizophrenia-concept was extremely broad in the United States. This might lead to a classification of concordance even if the respective clinical picture in a twin pair might be highly different. In Scandinavia, where one followed more or less a Kraepelinian classification, twin pairs where one twin is typical schizophrenic whereas the co-twin is borderline or severely neurotic, might be classified as discordant whereas such a pair might be designated concordant in USA. Finally, one has to correct for age if the pair has not passed the period of risk as to schizophrenia. Kallmann's original concordance rate for schizophrenia in MZ was 69 percent. The often cited figure of 86 percent was arrived at by using Weinberg's short method for calculation of the morbidity risk of the non-affective co-twin (Strømgren 1935). The risk period for schizophrenia is estimated to be 15-45 years, however, concordance within twin pairs usually occurs within a short period of time. By using the ordinary correction of age, one therefore will overcorrect for age, as did Kallmann. In scientific investigations sources of errors might go in various directions and thus counterbalance each other. In Kallmann's twin studies from the United States all the sources of error go in the same direction. Thus the concordance figure, in particular for $\mathrm{MZ}$, increases 
both because of sampling errors, doubtful psychiatric classification and overcorrection for age.

There are few studies of offspring of MZ twins discordant for schizophrenia, and the available samples are too small for a final conclusion. The studies of Fischer (1973) and Gottesman and Bertelsen (1989) dealing with offspring of discordantly affected MZ schizophrenics, have often been cited as strong evidence for a major genetic disposition to schizophrenia. However, the methodology of those studies is not acceptable for a series of reasons. For instance, Fischer grouped together offspring of both concordant pairs and offspring of index cases in discordant pairs and compared this group with offspring of co-twins in discordant pairs. In addition, the information of the offspring is scanty, and practically none of the offspring had been investigated personally. Finally, the sick twins in discordant pairs had almost three times more children than the healthy twins, an unlikely finding. See for instance, Kringlen and Cramer (1989) and Torrey (1990) for critical remarks.

\section{NORWEGIAN TWIN STUDIES}

During the 1960-70 years one witnessed a flourishing of twin research in Norway. A study of hospitalized schizophrenic twins by Kringlen (1964) observed that two of $8 \mathrm{MZ}$ pairs were concordant, in comparison two of $12 \mathrm{DZ}$, thus practically no difference between $\mathrm{MZ}$ and DZ with regard to concordance was observed. This unexpected result stimulated the author to establish a national twin register for the period 1901 to 1930 which was later extended back to 1895 and forward to 1945. The information was obtained from Statistics Norway. In Norway the local clergymen were for a long time entrusted with the task of reporting all births to the Bureau. Except for the years 1895-1900, the register is almost complete, and includes same-sexed and opposite-sexed twin-pairs, in total 37000 pairs.

In order to obtain a large and representative sample of psychotic twins the 25588 twin pairs born between 1901 and 1930 were subsequently checked with the Central Register of Psychosis which dated back to 1916. This register comprised all patients admitted to mental hospitals (asylums) and all psychotic patients admitted to psychiatric clinics and psychiatric units in general hospitals. In this way one obtained a large representative sample of psychotic twins, admitted to psychiatric institutions after age 15. My reason for choosing the particular period of 1901 through 1930 was that the obtained material would belong to the group 35 to 64 years of age, and would thus, for the most part be past the period of risk of schizophrenia, the study of which was the main object of this investigation. Of the 519 pairs obtained through the checking of the twin register with the psychosis register, 342 had a diagnosis of schizophrenia, manic depressive illness or reactive psychosis, and a co-twin alive at the age of 15 years. From these twins there were $55 \mathrm{MZ}$ and $90 \mathrm{DZ}$ pairs in which one or both twins had received a diagnosis of schizophrenia. A preliminary zygosity classification was established by asking for physical similarities. Was the identity of the twins confused with that of the co-twin when they were children? Were they as like as two drops of water? A final zygosity diagnosis was determined in most cases by blood tests, using ten of the most common serological systems at that time. If a same-sexed pair of twins is identical on these tens systems the chances that the pair is dizygotic will be less than two percent. (Today zygosity classification is usually determined by DNA tests.)

The study had three principal aims: first to obtain "true" concordance figures for all types of functional psychoses; second, to study problems pertaining to nosology; and third, to investigate a larger sample of discordant pairs to clarify, if possible, crucial environmental factors.

The concordance figure of schizophrenia was 25-38 per cent in MZ and 4-10 percent in DZ. The lower percentage was based upon registered hospitalized cases, the higher percentage was built upon personal investigation of the subjects by the author.

The twin partners of typical chronic schizophrenic cases displayed a wide specter of psychopathology. About 30 percent manifested the same type of psychopathology, 30-35 percent showed a picture with personality disorders and neurotic symptoms, the rest, about 30 percent, being clinically normal. Thus the clinical picture presented by individuals with the same genetic makeup as the schizophrenic embraces a graduated series of disorders and personality patterns that ranges from a duplication of the psychosis to personality disorders, neurosis and clinical normalcy.

The relatively low concordance figures in MZ twins with respect to schizophrenia show that the environmental contribution to the etiology is considerable. Human beings with the same genotype as the schizophrenic MZ twin have at least a 60 percent chance of escaping the illness. The environmental factors might be both of a somatic and of a social character. One has not, however, been able to demonstrate convincingly the specific nature of any environmental component. Such factors might be difficult to discover with the retrospective method. Any social factors are most likely difficult to disclose because they are probably due to interpersonal disturbances in social systems where cause and effect are interwoven in a series of multiple interactions. Various personality characteristics which are correlated with later schizophrenic development are formed in childhood as a result of interaction between genes and milieu. Usually the more introverted, the more submissive, the more dependent and the more obsessive twin is likely to develop schizophrenia. We are not, however, facing any rigid determinism because sometimes the apparently more healthy twin falls ill with the disease. 
In manic depressive cases one observed high concordance figures in $\mathrm{MZ}$ if a wide concept of manic depressive illness was used, but quite low figures with a strict concept of illness. In MZ pairs one often found the same tendency to manic or depressive fluctuations in both twins. One twin might undergo severe manic and/or depressive periods while the partner at times might experience milder elated and depressive periods without any need for treatment. Thus one might assume that there is a genetic disposition to emotional fluctuations, the strength of these fluctuations are, however, determined by environmental factors.

In reactive psychosis there was practically no difference in concordance rates between MZ and DZ (Kringlen 1967). According to to-day's ICD-10 classification, these cases would be diagnosed as schizophrenic or bipolar.

Kringlen et al has also studied offspring of discordant schizophrenic pairs. The sample consisted of 22 MZ pairs discordant for schizophrenia in which either the index twin and/or the co-twin had children. The index offspring came from 12 families, whereas the co-twin offspring came from 19 families. The index schizophrenic twins had 28 adult offspring, the nonpsychotic co-twins 45 offspring (Kringlen and Cramer, 1989). In the thoroughly investigated sample the number of schizophrenic subjects was higher in the offspring of MZ probands than in the offspring of nonschizophrenic co-twins, although the differences are not statistically significant (at the 5\% level). There was also a trend for the amount of particularly schizophrenic spectrum disorders to be lower in the offspring of non-psychotic co-twins than in the offspring of $\mathrm{MZ}$ index twins, which might point to an effect of environmental factors connected with rearing and family life.

\section{RECENT TWIN RESEARCH}

During the last forty years twin research in psychiatry has expanded considerably in Norway. In a clinical sample of anxiety states Torgersen (1983) and Skre et al (1993) reported clear differences in concordance rates between MZ and DZ. In a large-scale epidemiological sample that included twins and all types of sister and brothers, Tambs and Moum (1993) observed a surprisingly low genetic effect for anxiety states and common depression. In a study of personality disorders Torgersen (1984) found that genetic factors play a central role. In a comprehensive twin study of senile dementia Bergem et al (1997) documented that Alzheimer's disease is heavily genetically determined in contrast to vascular dementia.

During the last years twin research has also been an important theme at the Norwegian Institute of Public Health (Folkehelseinstituttet) where a number of twin researchers have been active in cooperation with other Norwegian and American scientists. A series of mental states from anxiety conditions to depression and eating disorders have been studied in large unselected samples of the general younger Norwegian population.

\section{REFERENCES}

Bergem AML, Engedal K, Kringlen E. The role of heredity in late-onset Alzheimer disease and vascular dementia. Arch Gen Psychiatry 1997; 54: 264-270.

Dalgard OS, Kringlen E. A Norwegian twin study of criminality. Br J Criminol 1976; 16: 213-232.

Fischer M. Genetic and environmental factors in schizophrenia. Acta Psychiatr Scand Suppl 1973; 238: 9-142.

Gjone H. A twin study of behaviour problems in children and young adolescents. Doctoral thesis. Oslo: University of Oslo, 1997.

Gottesman II, Bertelsen A. Confirming unexpressed genotypes for schizophrenia: risks in the offspring of Fischer's Danish identical and fraternal discordant twins. Arch Gen Psychiatry 1989; 46: 867-872.

Gottesman II, Shields J. Schizophrenia in twins: 16 years' consecutive admissions to a psychiatric clinic. $B r J$ Psychiatry 1966; 112: 809-818.

Kallmann FJ. The genetic theory of schizophrenia. An analysis of 691 schizophrenic twin index families. Am J Psychiatry 1946; 103: 309-322.

Kallmann FJ. The genetics of psychoses. An analysis of 1.232 twin index families. In: Congres International de Psychiatrie, Paris. VI. Psychiatrie Sociale Rapports. Paris: Herman \& Cie, 1950.

Kringlen E. Schizophrenia in male monozygotic twins. Oslo: Universitetsforlaget, 1964.

Kringlen E. Heredity and environment in the functional psychoses, Vol. and II. Oslo: Universitetsforlaget, 1967 and London: Heineman, 1968.

Kringlen E. Twins - still our best method. Schizophr Bull 1976; 2: 429-433.

Kringlen E, Cramer G. Offspring of monozygotic twins discordant for schizophrenia. Arch Gen Psychiatry 1989; 46: 873-877.

Luxenburger H. Vorlaufiger Bericht uber psychiatrische Serienuntersuchungen an Zwillingen. Z ges Neurol Psychiatr 1928; 116: 297-326.

Onstad S, Skre I, Torgersen S, Kringlen E. Twin concordance for DSM-III-R schizophrenia. Acta Psychiatr Scand 1991; 83: 395-401. 
Onstad S, Skre I, Torgersen S, Kringlen E. Subtypes of schizophrenia - evidence from a twin-family study. Acta Psychiatr Scand 1991; 84: 203-206.

Onstad S, Skre I, Torgersen S, Kringlen E. Birthweight and obstetric complications in schizophrenic twins. Acta Psychiatr Scand 1992; 85: 70-73.

Rosanoff AJ, Handy LM, Plesset IR, Brush S. The etiology of so-called schizophrenic psychoses. With special reference to their occurrence in twins. Am J Psychiatry 1934; 91: 247-286.

Rosenthal D. Problems of sampling and diagnosis in the major twin studies of schizophrenic twins. J Psychiatr Res 1962; 2: 116-134.

Siemens HW. Die Zwillingpathologie. Ihre Bedeutung, ihre Methodik, ihre bisherigen Ergebnisse. Berlin: Springer, 1924.

Skre I, Onstad S, Torgersen S, Kringlen E. A twin study of DSM-III-R anxiety disorders. Acta Psychiatr Scand 1993; 88: 85-92.

Slater E, with assistance of Shields J. Psychotic and neurotic illnesses in twins. London: Her Majesty's Stationery Office, 1953.

Strømgren E. Zum Ersatz des Weinbergschen “abgekurzten Verfahrens”. Zugleich ein Beitrag zur Frage von der Erblichkeit des Erkrankungsalters bei der Schizophrenie. Z ges Neurol Psychiatr 1935; 153: 784-797.

Tambs K, Moum T. Low genetic effect and age-specific family effect for symptoms of anxiety and depression in nuclear families, halfsibs and twins. J Affect Disord 1993; 27: 183-95.

Tienari P. Psychiatric illnesses in identical twins. Acta Psychiatr Scand 1963; 39 (Suppl 171): 1-195.

Torgersen S. Genetic factors in anxiety disorders. Arch Gen Psychiatry 1983; 40: 1085-1089.

Torgersen S. Genetic and nosological aspects of schizotypal and borderline personality disorder: a twin study. Arch Gen Psychiatry 1984; 41: 546-554.

Torgersen S. Genetic factors in moderately severe and mild affective disorders. Arch Gen Psychiatry 1986; 43: 222-226.

Østlyngen E. Psykologisk tvillingforskning og dens problemer. Oslo: Gyldendal, 1946.

Østlyngen E. Possibilities and limitations of twin research as a means of solving the problems of heredity and environment. Acta Psychol 1949; 6: 59-90. 